\title{
BMJ Open Quality Optimisation of hyperemesis gravidarum management through an emergency department setting
}

\author{
Graham Skalley, ${ }^{1}$ John Denny, ${ }^{2}$ Eve Allen, ${ }^{3}$ Shwetha Rao ${ }^{1}$
}

To cite: Skalley G, Denny J, Allen $\mathrm{E}$, et al. Optimisation of hyperemesis gravidarum management through an emergency department setting. BMJ Open Quality 2018;7:e000330. doi:10.1136/ bmjoq-2018-000330

- Additional material is published online only. To view please visit the journal online (http://dx.doi.org/10.1136/ bmjoq-2018-000330).

Received 9 January 2018 Revised 5 July 2018 Accepted 10 July 2018
Check for updates

(c) Author(s) (or their employer(s)) 2018. Re-use permitted under CC BY-NC. No commercial re-use. See rights and permissions. Published by BMJ.

${ }^{1}$ Emergency Department, Princess Royal University Hospital, Orpington, Kent, UK ${ }^{2}$ Department of General Medicine, Princess Royal University Hospital, Orpington, Kent, UK

${ }^{3}$ Obstetrics and Gynaecology Department, Princess Royal University Hospital, Orpington, Kent, UK

Correspondence to Dr Shwetha Rao; k1645513@kcl.ac.uk

\begin{abstract}
Hyperemesis gravidarum is a common condition characterised by severe nausea and vomiting. The referral process from the emergency department (ED) to obstetrics and gynaecology (0\&G) can lead to treatment delays before the gynaecology team review the patient, resulting in unnecessary prolonged inpatient stays in $0 \& G$. This quality improvement project created a clinical pathway which optimised care of patients presenting with hyperemesis gravidarum in the ED at the Princess Royal University Hospital using a treatment protocol. Two audits were carried out to assess improvements in patient care and reduction in admissions to 0\&G. Overall, admissions to $0 \& G$ were reduced by $68.7 \%$ (cycle 1 ) and $70.5 \%$ (cycle 2) compared with admission rates before the proforma, saving the trust an estimated $£ 265700$ and 235 bed days over a year.
\end{abstract}

\section{INTRODUCTION}

Hyperemesis gravidarum is a common condition which affects women during early pregnancy and is characterised by severe nausea and vomiting leading to dehydration. ${ }^{1}$ Consequently, mothers suffering with hyperemesis gravidarum commonly present to the emergency department (ED) and are initially treated there before being referred to the gynaecology team.

This referral process can lead to treatment delays before the gynaecology team reviews the patient. This often results in unnecessary prolonged inpatient stays on the gynaecology ward. This costly process can be optimised if patient management is streamlined through the use of ED clinical decision unit (CDU) beds. In 2015, a hyperemesis gravidarum CDU pathway was created at the Princess Royal University Hospital to effectively identify and treat hyperemesis gravidarum in the ED, with the aim of promptly treating patients on presentation and reducing the need for referrals to obstetrics and gynaecology (O\&G).

\section{BACKGROUND}

Nausea and vomiting are common, affecting women in up to $80 \%$ of pregnancies. Hyperemesis gravidarum represents the severe end of the spectrum and is associated with dehydration, weight loss of $>5 \%$ and electrolyte imbalance. ${ }^{2}$ Diagnosis is dependent on exclusion of other causes like gastritis and urinary tract infections and inclusion of those with ketones of four or more on urinalysis. It occurs in $0.3 \%-3.6 \%$ of pregnancies with variable recurrence rates between $15.2 \%$ and $81 \% .^{34}$

Hyperemesis gravidarum has several aetiological theories but is primarily associated with increased beta human chorionic gonadotropin hormone levels. ${ }^{2}$ It affects women in the first trimester of pregnancy, with symptoms peaking at approximately 9 weeks and mostly resolving by 20 weeks in $90 \%$ of women. $^{5}$

Treatment is supportive focusing on fluid, vitamin and electrolyte replacement as well as antiemetic therapy. ${ }^{6}$

One should not dismiss the increasing evidence which highlights the psychological burden of hyperemesis gravidarum, not to mention the financial cost to both the patient and the healthcare system. ${ }^{7}$

\section{BASELINE MEASUREMENT}

A snapshot retrospective analysis of patients who presented with nausea and vomiting in pregnancy was performed in August 2015, covering attendances from 1 May 2015 to 31 July 2015. At the time of the initial data collection, the existent policy was to refer all patients with greater than four ketones on their urine dipstick and any patient too symptomatic to tolerate oral fluids to the O\&G team. Less symptomatic patients with fewer ketones were managed in the ED with a low threshold for admission if no improvement.

Our initial data analysis (table 1) showed that a major proportion of those patients referred to the O\&G team were admitted following a prolonged stay in the ED while awaiting suitable ward beds. The treatment of these patients was not consistent and not always in line with best management 


\begin{tabular}{lccc}
$\begin{array}{l}\text { Table } 1 \\
\text { introduction of the pathway }\end{array}$ & Yes & No & $\%$ \\
\hline Parameter & 9 & 11 & 45 \\
\hline Pregnancy confirmed & 5 & 15 & 25 \\
Blood glucose & 16 & 4 & 80 \\
Antiemetics prescribed & 0 & 20 & 0 \\
Folic acid prescribed & 0 & 20 & 0 \\
Thiamine prescribed & 0 & 20 & 0 \\
$\begin{array}{l}\text { Thromboprophylaxis } \\
\text { prescribed }\end{array}$ & & & \\
Intravenous fluid prescribed & 20 & 0 & 100 \\
$\begin{array}{l}\text { Admitted to obstetrics and } \\
\text { gynaecology }\end{array}$ & 15 & 5 & 75 \\
\hline
\end{tabular}

protocols. These patients formed a major volume of referrals to the O\&G team and the subsequent length of stay on the wards was averaging approximately 2.4 days. Seventy-five per cent ( 15 out of 20 patients) were admitted to O\&G in the 3-month period covered.

We concluded that the baseline measurement for this project indicated that there was a high admission rate to O\&G, treatment delays due to slow availability of beds and a prolonged inpatient stay. This led to suboptimal management and could have contributed to poor patient experience, although this was not measured at the time of our study.

\section{Pre-pro forma results}

\section{DESIGN}

A new clinical pathway for the treatment of hyperemesis gravidarum in the ED was introduced on 15 September 2015. This quality improvement project was initiated by clinicians in the ED and O\&G teams to improve the quality of care for patients presenting with hyperemesis gravidarum. The project included the development of a guideline and a pathway for the management of these patients in the ED short stay unit called CDU. This care pathway facilitates the effective management of hyperemesis gravidarum within the ED by admitting the patient to $\mathrm{CDU}$ rather than to the $\mathrm{O} \& \mathrm{G}$ ward, with the aim of treatment up to a maximum of 24 hours.

This pathway was developed after collaborative work between the ED and O\&G teams and resulted in the introduction of the hyperemesis pathway in CDU. A working group was created involving senior members of the ED and O\&G teams including consultants in ED and $O \& G$, clinical nurse specialists in $O \& G$ and senior ED nursing staff. The group met often and initially started off revising the existing guideline for the management of patients with hyperemesis in the hospital. The new guideline developed was based on the latest Royal College of Obstetrics and Gynaecology guidelines for the management of hyperemesis gravidarum. ${ }^{3}$ Following this, we decided to create a pathway for management of these patients on the CDU and this involved writing up a proforma which guided all medical staff regarding suitability for admission to $\mathrm{CDU}$ and indications for referral and admission to the O\&G team (online Supplementary appendices 1 and 2).

This pathway was circulated and agreed by the senior clinical team of the respective departments and introduced in September 2015. We planned to conduct a reaudit soon after the introduction of this pathway and complete two PDSA cycles to establish good practice. We aimed to look for improvements in patient care, reduction in admissions to O\&G and adherence to the proforma.

The audited parameters included investigations, urinalysis and confirmation of pregnancy, blood glucose measurement and blood tests, administration of intravenous fluids; antiemetics, folic acid, thiamine, thromboprophylaxis and discharge outcome, as well as the length of stay in the ED.

The patient inclusion criteria:

- Patient discussed with an ED consultant or senior.

- Pregnancy confirmed.

- Two or more ketones in urine.

- No alternative diagnosis more likely than hyperemesis.

The patient exclusion criteria:

- Haemodynamic instability.

- Associated urinary tract infection.

- Presence of abdominal pain or per vaginal bleeding.

- Gross electrolyte imbalance.

We decided to use the pre-pro forma results as our baseline measurement and later conduct two PDSA cycles from 15 September 2015 to 30 November 2015 and again from 1 May 2016 to 21 August 2016. A total of 93 patients were included across all audits.

\section{STRATEGY}

In order to embed the new pathway, we decided to do a series of educational sessions for the clinical staff of both ED and O\&G. All existing clinical staff were informed about the pathway at their teaching sessions and audit afternoons. New junior doctors rotating through the ED were taught about managing hyperemesis gravidarum in conjunction with the use of the new pathway during their induction teaching sessions. The validity of the management was supported by guidance from the O\&G department.

The pathway (online Supplementary appendix 2) was introduced in conjunction with the pro forma (online Supplementary appendix 1) which is a mandatory admission document for CDU and is easily available electronically from the clinical guidance folder in the ED. This pro forma functions as an admission document and serves to guide investigations, suggest treatment regimen and lays out criteria for discharge. It was an already established practice in our ED that any patient admitted to $\mathrm{CDU}$ required a completed pro forma, signed and reviewed by an ED senior doctor. This helped ensure that the pro forma criteria were adhered to and the treatment 
plan was successfully followed through. We also empowered our nurses on CDU to challenge any medical staff if the pro forma was not followed through.

\section{PDSA cycle 1 (15 September 2015-30 November 2015)}

This was initiated as a retrospective collection of data 3 months after the introduction of the pathway. We reviewed compliance with the pro forma and admission rates to O\&G during this period. We also looked at length of the stay of patients who were admitted to an O\&G ward and compared that with length of stay when admitted to CDU.

We collected data for a total of 29 patients during this period. The audit showed a drastic reduction in length of stay when patients were admitted to CDU and it prompted us to repeat the PDSA cycle to ensure that changes were consistent and sustained.

Following this cycle, we made some changes to the pathway which included changes to the first choice of antiemetic from cyclizine to ondansetron. We also recognised the need for more education regarding the importance of thromboprophylaxis in pregnant women and this was delivered through teaching sessions and by empowering the nurses on $\mathrm{CDU}$ to challenge doctors regarding its prescription for patients admitted longer than 8 hours. Three months following the introduction of the pathway, the feedback we received from the ED clinical staff was very encouraging and we noticed that they were more comfortable managing these women in CDU.

\section{PDSA cycle 2 (1 May 2016-21 August 2016)}

This reaudit was conducted 6 months after the previous audit. We collected data for a total of 44 patients in this cycle. Following this cycle, there were few changes that were made. A major change done to the pathway was to remove the need for a mandatory referral to the O\&G clinical nurse specialist for all patients admitted with hyperemesis to CDU but instead use their services for patients who are refractory to treatment. We also revised our discharge criteria to include referral for an ultrasound scan as an outpatient and prescription of appropriate antiemetic's to take home.

The pro forma in its final form has evolved over time since its introduction after feedback from the staff working in the O\&G department and ED and is currently been seen as a very successful pathway for patients admitted to CDU.

\section{RESULTS}

PDSA cycle 1 (table 2) showed that there was an overall improvement in the medical management of patients presenting with hyperemesis gravidarum. In particular, of note, we saw an improvement in prescription of antiemetic's in line with the hospital guideline and also noticed improvement in prescription of vitamins and thromboprophylaxis. The remarkable improvement was a drop in admissions to O\&G, reduced by $68.7 \%$ in cycle 1 and
Table 2 Results of the data collected over the two cycles and its comparison with the baseline measurement

\begin{tabular}{|c|c|c|c|}
\hline Parameter & $\begin{array}{l}\text { Pre-pro } \\
\text { forma, \% }\end{array}$ & Cycle 1, \% & Cycle 2, \% \\
\hline Pregnancy confirmation & 45 & 79.3 & 74.4 \\
\hline Blood glucose & 25 & 31 & Not assessed \\
\hline Folic acid and thiamine & $0 \%-0$ & $24 . \%-17.2$ & $65.1 \%-62.8$ \\
\hline $\begin{array}{l}\text { Enoxaparin } \\
\text { (admission >8 hours) }\end{array}$ & 0 & 10.3 & 52 \\
\hline $\begin{array}{l}\text { TED stockings } \\
\text { (admission }>8 \text { hours) }\end{array}$ & 0 & 0 & 40 \\
\hline Antiemetics prescribed & 80 & 100 & 97.7 \\
\hline Ketone urinalysis & 90 & 100 & 97.7 \\
\hline Intravenous fluid prescribed & 100 & 100 & 100 \\
\hline $\begin{array}{l}\text { Admitted to obstetrics and } \\
\text { gynaecology }\end{array}$ & 75 & 6.9 & 4.5 \\
\hline
\end{tabular}

TED, thrombo-embolic deterrent.

$70.5 \%$ in cycle 2 compared with admission rates before the introduction of the pathway.

The medical management of hyperemesis patients has remained at an improved standard over the next year. The reduction in admissions since the introduction of the pathway is statistically significant with $p<0.001$ (online Supplementary appendix 3).

In the 3 months post-introduction PDSA cycle 1, 6.9\% (2 out of 29 patients) were admitted to O\&G. This was consistent in the cycle 2 , with $4.5 \%$ (2 out of 44 patients) admitted to O\&G (table 2). The two patients who were admitted to the O\&G team in both the cycles failed to improve with the 20 hours treatment they received in $\mathrm{CDU}$ and hence required referral for ongoing treatment and further specialist input from the O\&G team.

The measured average length of stay prior to introduction of this pathway was about 2.4 days on the O\&G wards and this reduced to an average length of stay of about 12 hours post-pathway on CDU. This reduction in length of stay is likely due to early recognition of the patient in ED, timely initiation of treatment which was in accordance with guideline, frequent nursing assessments and re-evaluations which were made available on CDU. The nursing staff on CDU were also provided with a clear criterion for discharge which helped identify patients' who were fit for discharge earlier than they would have been on the O\&G wards.

\section{LIMITATIONS}

Each of the PDSA cycles included a different number of patients from which data were collected; this could be due to variable amounts of patients presenting to ED with hyperemesis gravidarum during the measurement periods. We collected the data for a 3-month block rather than including a set number of patients. We are unable to explain the reason for this variability. It is worth noting that in cycle 2, there seemed to be double the number of patients (44) compared with the previous data (29) and 
this could be due to an increased familiarity in the use of the pathway and therefore more patients were admitted on to the short stay unit rather than in the main ED. We believe that this indirectly helped divert patients away from the ED and helped create capacity for more unwell patients to be treated in the ED.

A second limitation would be that we were unable to comment on the care that the patients with hyperemesis gravidarum received after admission to an O\&G ward as their medical notes on admission to O\&G were not audited before the introduction of the pathway. By reviewing the online patient management database, we were only able to confirm that the average length of stay was more on the O\&G wards (2.4 days) and this was reduced post-introduction of the pathway. We can only assume that this may have contributed to a better patient experience as this data was not collected during the audits.

\section{CONCLUSIONS}

The introduction of the hyperemesis gravidarum pathway and its use 1 year since introduction has been very successful. The collaborative work between $\mathrm{ED}$ and the $\mathrm{O} \& \mathrm{G}$ team throughout the project helped bring consistent improvements to the pathway and optimised the management of hyperemesis gravidarum at Princess Royal University Hospital.

We believe that the success of this pathway and pro forma could be attributed to the fact that rather than being a simple tick-box admission sheet, it serves as a clinical guide to managing hyperemesis gravidarum to the standards set out by the Royal College of Obstetrics and Gynaecology. This encourages its use by junior doctors, as most rotating into emergency medicine will most likely not have had much prior experience of managing hyperemesis.

In the 3-month period PDSA cycle 2 measured, the pathway had saved the O\&G department an estimated $£ 66425$ as a result of reduced admissions and length of stay. This is based on the average length of stay for a hyperemesis patient in 2015 being 2.4 days prior to the pathway, and an acute obstetrics bed costing $£ 838.70$ per day. Over a year, this could save an estimated $£ 265700$ even after factoring in the costs for the management of these patients in CDU. The reduction in emergency admissions improves patient care by freeing up inpatient beds and releasing O\&G staff for elective admissions and procedures. Audit suggests that over a year, at least 235 bed days have been saved due to this pathway. In the future, we plan to have nurse-led criteria-based discharges of these patients to prevent further delays and improve efficiency.

Acknowledgements The authors would like to thank Ms Barbara Healy, Gynaecology Matron; Mrs Lisa Lee, Deputy Head of Nursing for Obstetrics and Gynaecology and Dorthe Swaby Larsen, Deputy Head of Nursing Emergency Department.

Contributors SR and EA contributed to the conception or design of the work, critical revision of the article and final approval of the version to be published. GS and JD contributed to data collection, data analysis, interpretation and drafting the article.

Funding The authors have not declared a specific grant for this research from any funding agency in the public, commercial or not-for-profit sectors.

Competing interests None declared.

Provenance and peer review Not commissioned; externally peer reviewed.

Open access This is an open access article distributed in accordance with the Creative Commons Attribution Non Commercial (CC BY-NC 4.0) license, which permits others to distribute, remix, adapt, build upon this work non-commercially, and license their derivative works on different terms, provided the original work is properly cited, appropriate credit is given, any changes made indicated, and the use is non-commercial. See: http://creativecommons.org/licenses/by-nc/4.0/.

\section{REFERENCES}

1. Niebyl JR. Nausea and vomiting in pregnancy. N Engl J Med Overseas Ed 2010;363:1544-50.

2. Einarson TR, Piwko C, Koren G. Quantifying the global rates of nausea and vomiting of pregnancy: a meta analysis. J Popul Ther Clin Pharmacol 2013;20:e171-83.

3. RCOG. Green-top guideline No. 69. The management of nausea and vomiting of pregnancy and hyperemesis gravidarum Royal College of Obstetricians and Gynaecologists, 2016.

4. Trogstad LI, Stoltenberg C, Magnus P, et al. Recurrence risk in hyperemesis gravidarum. BJOG 2005;112:1641-5.

5. Gadsby R, Barnie-Adshead AM, Jagger C. A prospective study of nausea and vomiting during pregnancy. $\mathrm{Br} J$ Gen Pract 1993;43:245-8. Erratum appears in Br J Gen Pract 1993;43:325.

6. Campbell K, Rowe H, Azzam H, et al. The management of nausea and vomiting of pregnancy. J Obstet Gynaecol Can 2016;38:1127-37.

7. Kramer J, Bowen A, Stewart N, et al. Nausea and vomiting of pregnancy: prevalence, severity and relation to psychosocial health. MCN Am J Matern Child Nurs 2013;38:21-7. 